BACKground: Isoferulic acid (IFA) is a main active ingredient of the rhizoma of Cimicifuga beracleifolia, which is used frequently in Japanese traditional medicine as an anti-inflammatory drug. It has been revealed that IFA inhibits the production of macrophage inflammatory protein-2 (MIP-2), which is a murine counterpart of the chemokine family that may contribute to the pathogenesis of inflammatory diseases through the chemotactic activity for inflammatory and immune effector cells.

Aim of the study: In this study, we investigated the therapeutic effect of IFA on the progression of lethal influenza virus pneumonia in mice by comparison with that of dexamethasone (DX), a potent inhibitor for various inflammatory cytokines including MIP-2. Metbods: Mice were infected by intranasal inoculation of influenza virus under ether anesthesia. The IFA or DX was given by oral administration once daily for 4 days after infection. After infection, the survival rate and the change in body weight were daily monitored.

Results: IFA administration markedly improved the survival rate and body weight loss of influenza virusinfected mice in a suitable dose range $(0.5 \mathrm{mg} / \mathrm{day})$. However, DX administration did not show a beneficial effect at any dose.

Conclusion: These data suggested that IFA is a novel tool not only for the intervention therapy, but also for the studies on the pathogenesis of influenza virusinduced pneumonia.

Key words: Isoferulic acid, Influenza virus, MIP-2, Chinese herbal medicine

\section{Administration of isoferulic acid improved the survival rate of lethal influenza virus pneumonia in mice}

\author{
Shinya Sakai, ${ }^{1, C A}$, Hiroshi Ochiai ${ }^{2}$, Naoki Mantani ${ }^{1}$, \\ Toshiaki Kogure ${ }^{1}$, Naotoshi Shibahar $a^{3}$ and \\ Katsutoshi Terasawa ${ }^{1}$ \\ ${ }^{1}$ Department of Japanese Oriental Medicine, \\ ${ }^{2}$ Department of Human Science, and ${ }^{3}$ Department of \\ Kampo Diagnostic, Toyama Medical and \\ Pharmaceutical University, 2630 Sugitani, Toyama \\ 930-0194, Japan
}

${ }^{\mathrm{CA}}$ Corresponding Author
Tel: +81764347393
Fax: +81764340366
E-mail: shinyas@ms.toyama-mpu.ac.jp

\section{Introduction}

Respiratory infections are particularly common in older persons, and influenza and pneumonia are major causes of morbidity and mortality. ${ }^{1}$ We have previously reported that macrophage inflammatory protein-2 (MIP-2), a murine counterpart of the chemokine family, ${ }^{2}$ plays a crucial role in the pathogenesis of a lethal influenza virus pneumonia in mice, and the administration of anti-MIP-2 antibody improved the survival rate of the infected mice. ${ }^{3}$

The rhizoma of Cimicifuga spp., such as Cimicifuga beracleifolia Komarov and Cimicifuga daburica Maxim are used frequently as antipyretic, analgesic and anti-inflammatory drugs in Japanese traditional medicine. Especially, isoferulic acid (IFA), 3-(3-hydroxy-4-methoxyphenyl)-2-propenic acid, has been recognized as the main active component of $C$. beracleifolia extract in the inflammation model in rats. ${ }^{4}$ Furthermore, we previously reported that IFA inhibited influenza virus-induced MIP-2 production in vitro and in vivo. ${ }^{5}$ Considering the pathological role of chemokine-induced neutrophil infiltration on vari- ous animal inflammation models, IFA might exhibit a beneficial effect on the lethal influenza virus pneumonia in mice. In this study, we investigated whether IFA administration improves the survival rate of influenza infected mice by comparing with administration of dexamethasone (DX), which is a potent inhibitor of MIP-2 production. ${ }^{5,6}$

\section{Materials and methods}

\section{Preparation of drugs}

IFA, purchased from Carl Roth GmbH (Karlsruhe, Germany), was freshly prepared in serum-free phosphate-buffered saline (PBS) at a concentration of $5 \mathrm{mM}$. The dissolved drugs were sterilized by filtration before use. DX, purchased from Sigma (St. Louis, MO, USA), was also dissolved in PBS at a concentration of $2.0 \mathrm{mg} / \mathrm{ml}$ and stored at $-80^{\circ} \mathrm{C}$ until use.

\section{Preparation of virus}

The lung-adapted strain of influenza A/PR/8/34 (PR8) virus (H1N1 subtype) was propagated in the 
chorioallantoic cavity of 10-day-old embryonated hen eggs for $48 \mathrm{~h}$ at $35^{\circ} \mathrm{C}$. The chorioallantoic fluid was collected and stored in small portions at $-80^{\circ} \mathrm{C}$ after centrifugation at $1000 \times g$ for $10 \mathrm{~min}$. The virus titer of the chorioallantoic fluid was $1.9 \times 10^{8}$ plaque forming units (PFU) as determined on Mardin-Darby canine kidney cells, as described previously. $^{\top}$

\section{Virus infection of mice and administration of drugs}

An outbred specific pathogen free strain of ICR female 4-week-old mice (body weight, approximately $17 \mathrm{~g}$ ) obtained from SLC Co. Ltd. (Hamamatsu, Japan) were used for infection by intranasal inoculation of a virus solution containing $4000 \mathrm{PFU} / 25 \mu 1$ (four $50 \%$ lethal doses of virus) under ether anesthesia. The IFA was given by oral administration $(0.5 \mathrm{ml} /$ mouse $)$ at doses of $0.25 \mathrm{mg} /$ day (group A), $0.5 \mathrm{mg} /$ day (group B) and $1.0 \mathrm{mg} /$ day (group C) once daily for 4 days on days 0 (just before infection), 1, 2 and 3 after infection. The DX was administered intraperitoneally $(0.5 \mathrm{ml} /$ mouse) at doses of $4.0,0.4$ and $0.04 \mathrm{mg} /$ day by the same manner as already described. As a control, mice received $0.5 \mathrm{ml}$ PBS via oral or intraperitoneal administration instead of IFA or DX, respectively. After infection, the survival rate was daily monitored and the change in body weight, a sensitive indicator of the progression of viral pneumonia in mice, was also monitored.

\section{Statistical analysis}

The data of survival rate and body weight were assessed by Fisher's exact probability test and unpaired $t$-test, respectively.

\section{Results and discussion}

In our previous report, the MIP-2 level in lung tissue obtained from influenza infected mice had a peak on day 2 and then sharply decreased. ${ }^{3}$ Based on this finding, IFA or DX was administered four times from day 0 to day 3 after infection. As shown in Figure 1A, the untreated control mice began to die on day 8 and mortality rates successively increased until day 10 . The mice in group B $(0.5 \mathrm{mg} / \mathrm{day}$ IFA $)$ also began to die on day 8 but mortality rates increased gently and, later than 10 days after infection, the survival rates of group B were significantly improved from those of the control group. In group A $(0.25 \mathrm{mg} / \mathrm{day}$ IFA), a beneficial effect on the survival rates $(P=$ $0.016)$ was slightly observed on the limited period after infection (days 10 and 11) but, in group C $(1.0 \mathrm{mg} / \mathrm{day}$ IFA), no effect was observed throughout
A

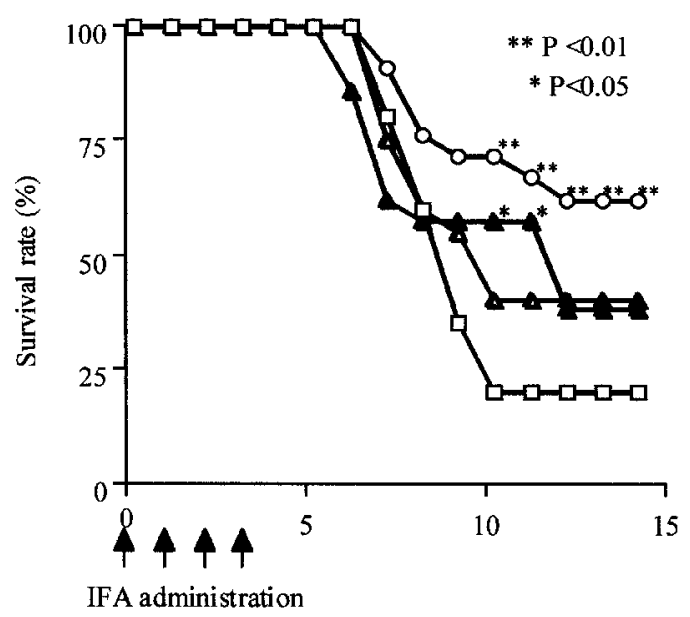

Days after infection

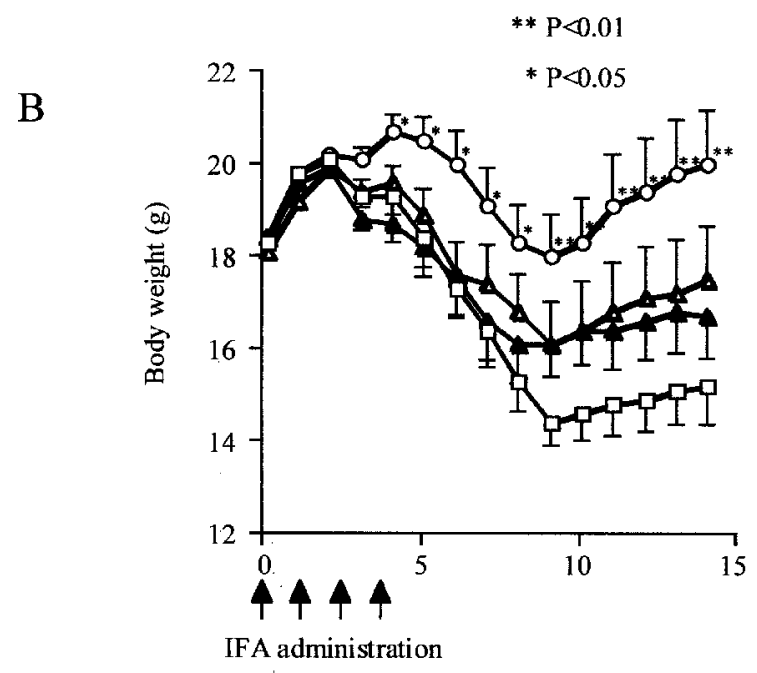

Days after infection

FIG. 1. (A) Effect of isoferulic acid (IFA) administration on the survival rate of influenza virus-infected mice. The IFA was given by oral administration at doses of $0.5 \mathrm{mg} /$ day (group $A$, filled triangle), $1.0 \mathrm{mg} /$ day (group $B$, open circle) and $2.0 \mathrm{mg} /$ day (group $\mathrm{C}$, open triangle) once daily during the initial 4 days (0-3 days after infection). As a control (open square), phosphate-buffered saline was given in the same manner. The data from 20 to 21 mice in each group were assessed by Fisher's exact probability test. * Significant difference from the control with the indicated $P$ value. (B) Effect of IFA administration on body weight loss of influenza virusinfected mice. The changes in body weight of the infected mice in each group shown in (A) were daily monitored and expressed as the mean \pm SE (error bar) using the same symbols as (A). The data were assessed by unpaired $t$-test. * Significant difference from the control with the indicated $P$ value.

the experiment. These data indicate that IFA has a window (a suitable dose range) for exhibiting the therapeutic effect for this infection model. The beneficial effect of IFA administration was also shown in body weight loss (Fig. 1B). The body weight loss of group B mice was significantly milder than that of the control group on day 4 and thereafter. Although there was no statistical differ- 
A

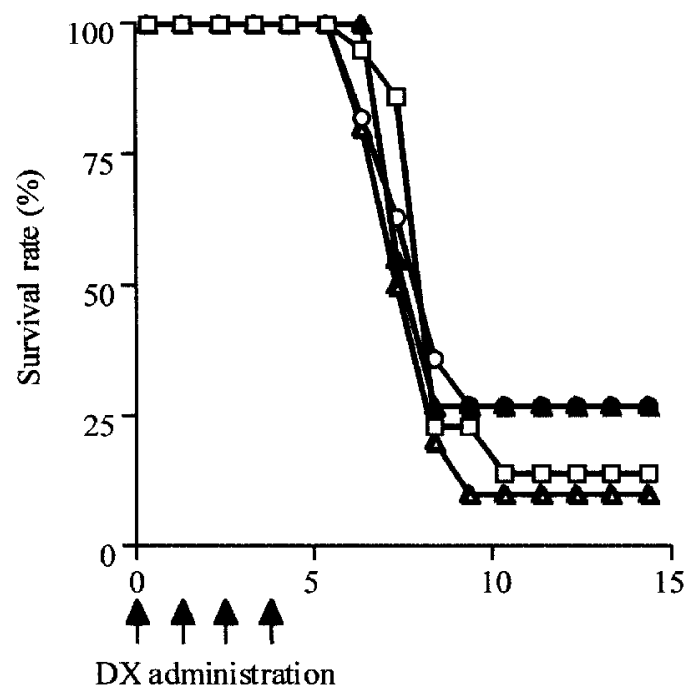

Days after infection

B

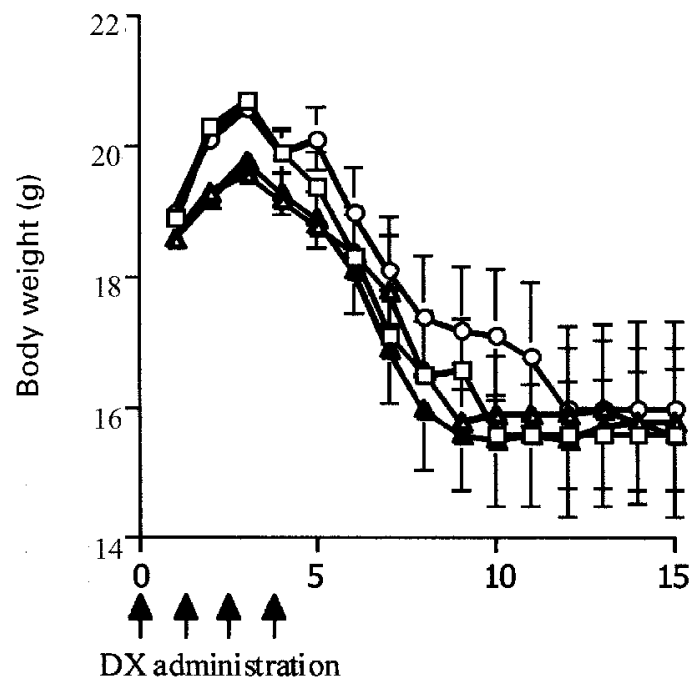

Days after infection

FIG. 2. Effect of dexamethasone (DX) administration on the survival rate of influenza virus-infected mice. DX was administrated intrapenitonealy at doses of $4.0 \mathrm{mg} / \mathrm{day}$ (filled circle), $0.4 \mathrm{mg} /$ day (open circle) and $0.04 \mathrm{mg} /$ day (open triangle) once daily during the initial 4 days $(0-3$ days after infection). As a control (open square), phosphate-buffered saline was given in the same manner. The data from 10 to 11 mice in each group were assessed by Fisher's exact probability test. (B) Effect of DX administration on body weight loss of influenza virus-infected mice. The changes in body weight of the infected mice in each group shown $(A)$ were monitored daily and are expressed as the mean \pm SE (error bar) using the same symbols as (A). The data were assessed by unpaired $t$-test.

ence, the body weight of mice in groups $\mathrm{A}$ and $\mathrm{C}$ changed with a tendency of milder loss than that of control. In this connection, it has been confirmed that IFA administration $(1.0 \mathrm{mg} / \mathrm{day})$ did not influence the body weight changes of uninfected ICR mice during the experimental period (data not shown).

Because it is well known that DX is a potent inhibitor for the production of various inflammatory cytokines including MIP-2, and also inhibits immunological reaction, i.e. antibody production, ${ }^{8,9}$ we further studied the effect of DX on the influenza virusinduced pneumonia in mice. However, in sharp contrast to IFA, DX did not improve either the survival rates or body weight loss at any doses (Fig. 2).

In summary, we have clearly demonstrated in this study that IFA, but not DX, has a potential to exhibit a therapeutic effect on the progression of lethal influenza virus pneumonia in mice. It has been shown that tissue-toxic molecules such as nitric oxide and active oxygen radicals are involved in the pathogenesis of influenza virus pneumonia in mice, and these tissue-toxic molecules are produced by neutrophils, especially chemokine-attracted neutrophils. ${ }^{3,10-13}$ We previously reported that IFA inhibited influenza virus-induced MIP-2 production in vitro and in vivo. ${ }^{5}$ These findings might permit speculation that IFA exhibits its therapeutic effect via reduction of MIP-2 production, and thereby by reduction of neutrophil accumulation at the infected sites. On the contrary, several studies have indicated that neutrophils may play a protective role by limiting virus spread in the early phase of infection and phagocytized influenza virions. ${ }^{14,15}$ Thus, the window effect of IFA shown in this study might reflect, in part, that the progression of influenza virus pneumonia in mice lay on the balance of adverse and beneficial roles of neutrophils. Taking these facts together with our findings, it is evident that IFA is not only a novel drug for the intervention therapy, but also an attractive drug for further studies on the pathogenesis of influenza virus pneumonia in mice.

\section{References}

1. Pinner RW, Teutsch SM, Simonsen L, Klug LA, Graber JM, Clarke MJ, Berkelman RL. Trends in infectious diseases mortality in the United States. JAMA 1996; 275: 189-193.

2. Driscoll KE. Macrophage inflammatory proteins: biology and role in pulmonary inflammation. Exp Lung Res 1994; 20: 473-490.

3. Sakai S, Kawamata H, Mantani N, Kogure T, Shimada Y, Terasawa K, Sakai $\mathrm{T}$, Imanishi N, Ochiai H. Therapeutic effect of anti-macrophage inflammatory protein 2 antibody on influenza virus-induced pneumonia in mice. J Virol 2000; 74: 2472-2476.

4. Shiotani Y, Terasawa K, Miyashiro H. Studies on the anti-inflammatory effects of Chinese crude drugs Shoma (Cimicifuga Rhizoma). J Med Pharm Soc Wakan-Yaku 1993; 10: 110-117.

5. Hirabayashi T, Ochiai H, Sakai S, Nakajima K, Terasawa K. Inhibitory effect of ferulic acid and isoferulic acid on murine interleukin-8 production in response to influenza virus infections in vitro and in vivo. Planta Med 1995; 61: 221-226.

6. Sakai S, Ochiai H, Nakajima K, Terasawa K. Inhibitory effect of ferulic acid on macrophage inflammatory protein- 2 production in a murine macrophage cell line, RAW264.7. Cytokine 1997; 9: 242-248.

7. Ochiai H, Ikesue A, KurokawaM, Nakajima K, Nakagawa H. Enhanced production of rat interleukin-8 by in vitro and in vivo infections with influenza A NWS virus. J Virol 1993; 67: 6811-6814.

8. Barnes PJ, Adcock I. Anti-inflammatory actions of steroids: molecular mechanisms. Trends Pharmacol Sci 1993; 14: 436-441. 
9. Johnson WJ, Muirhead KA, Meunier PC, Votta BJ, Schmitt TC, DiMartino MJ, Hanna N. Macrophage activation in rat models of inflammation and arthritis. Systemic activation precedes arthritis induction and progression. Arthritis Rbeum 1986; 29: 1122-1130.

10. Akaike T, Noguchi Y, Ijiri S, Setoguchi K, Suga M, Zheng YM, Dietzschold B, Maeda H. Pathogenesis of influenza virus-induced pneumonia: involvement of both nitric oxide and oxygen radicals. Proc Natl Acad Sci USA 1996; 93: 2448-2453.

11. Moncada S, Palmer RM, Higgs EA. Nitric oxide: physiology, pathophysiology, and pharmacology. Pharmacol Rev 1991; 43: 109-142.

12. Oda T, Akaike T, Hamamoto T, Suzuki F, Hirano T, Maeda H. Oxygen radicals in influenza-induced pathogenesis and treatment with pyran polymer-conjugated SOD. Science 1989; 244: 974-976.

13. Blake DR, Hall ND, Bacon PA, Dippe PA, Halliwell B, Gutteridge JM Effect of a specific iron chelating agent on animal models of inflammation. Ann Rbeumat Dis 1983; 42: 89-93.

14. Ratcliffe D, Migliorisi G, Cramer E. Translocation of influenza virus by migrating neutrophils. Cell Mol Biol 1992; 38: 63-70.

15. Ratcliffe DR, Nolin SL, Cramer EB. Neutrophil interaction with influenzainfected epithelial cells. Blood 1988; 72: 142-149.

\section{Received 6 February 2001; accepted 22 February 2001}




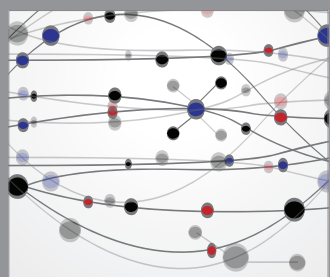

The Scientific World Journal
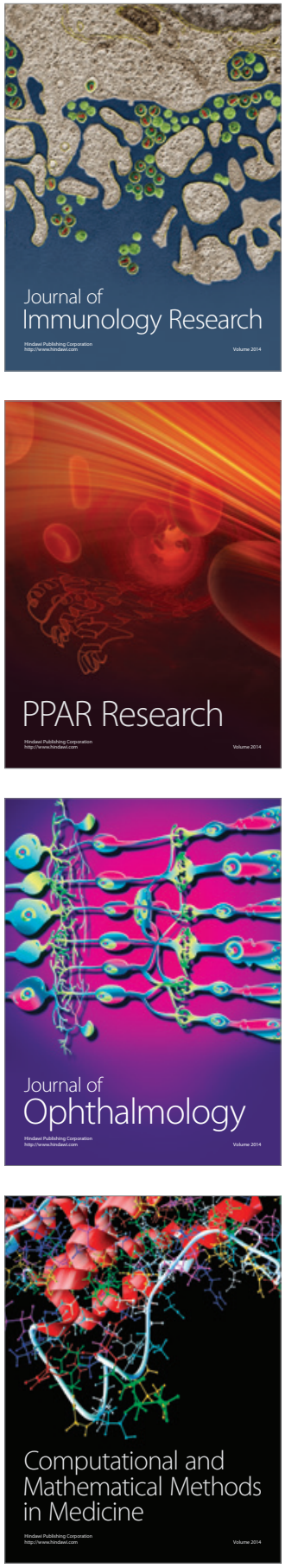

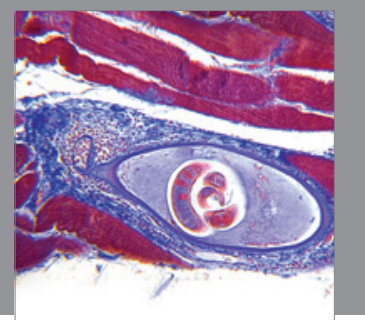

Gastroenterology

Research and Practice
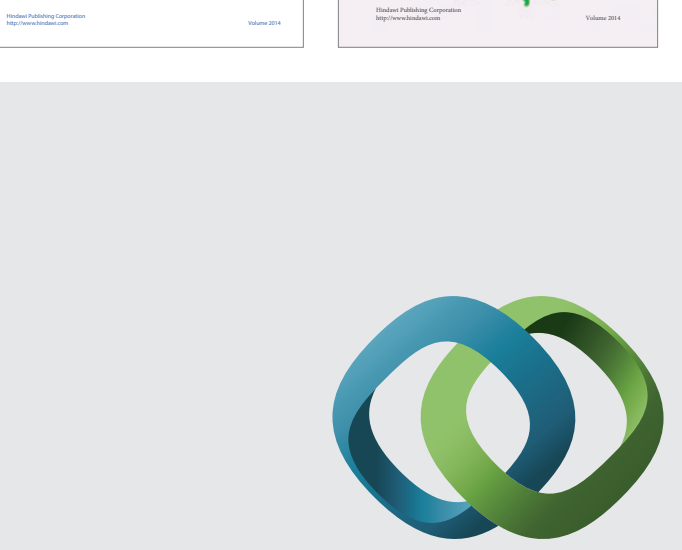

\section{Hindawi}

Submit your manuscripts at

http://www.hindawi.com
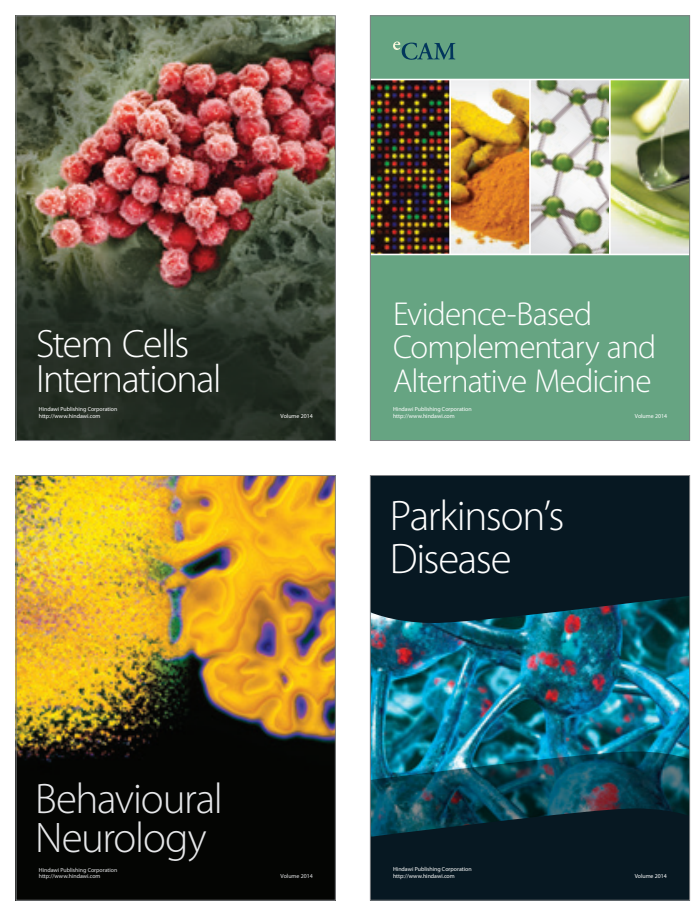

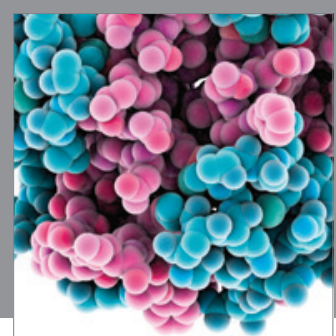

Journal of
Diabetes Research

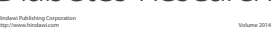

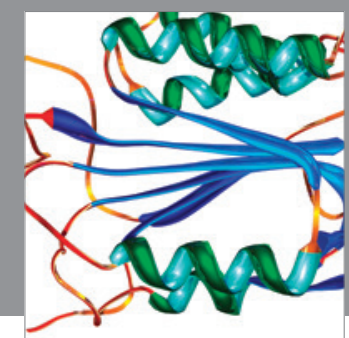

Disease Markers
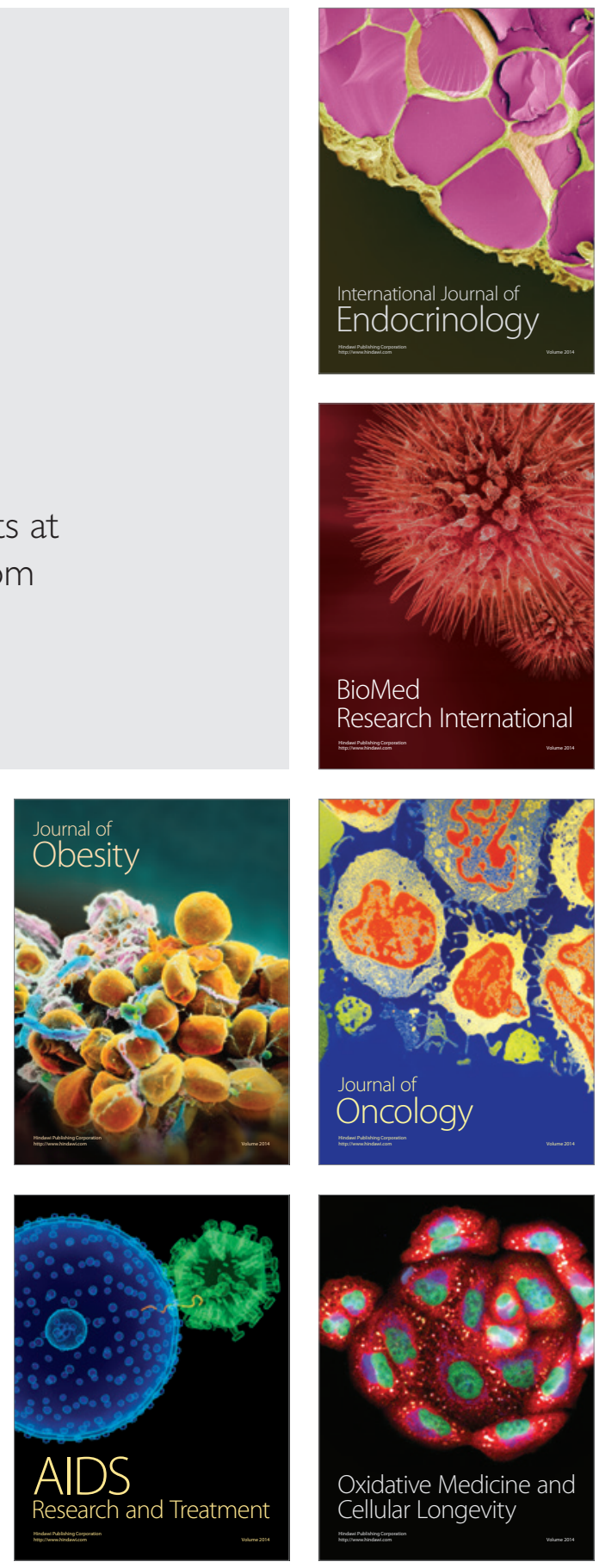